\title{
Study on the Gender Characteristics and the Level of Mental health of Students in the Private College Ling YAN
}

The College of Post and Telecommunication of WIT, Wuhan, China

Yanling59@126.com

Keywords: Students of the private college, Mental health, Gender characteristics

Abstract: Objective: To explore gender characteristics and the level of mental health of Students in the private college. Methods: 2441 private college students were assessed with SCL-90 questionnaire. Results: Interpersonal-sensitivity and obsessive-compulsive were main problems in these students. The significant differences were existed in factor of Phobia, Depression, and Anxiety between male and female students. Those students who have different mental health level have significant different coping style as well. Conclusion: Female students were subject to mental problems in Phobia, Depression, and Anxiety.

\section{Introduction}

Applied technology education of the private College is changing to fall the focus on teaching of working skill. Compared with other groups, students in private college for professional orient are special in learning job skills, which are directly related to their vocation. Previous research has found that financial pressures can be a significant factor in causing individuals stress ${ }^{[1][2][4][5]}$. In that case, they should conform more directly market competition and stress than ordinals college students. On the other hand, the students are generally lower in study motivation, poorer in study foundation and worse in study custom than the ordinary college fresh. In view of the above two, the students are easily to loss the psychology balance so as to result in mental and/or general health problems.

This article is to explore the differences of the gender characteristics and mental health in psychological mental level distinguishes the effective coping style, according to which the students educated to adopt the effective coping style consciously to be psychological health. Thus getting rid of hard puzzle, they would pass through the psychological crisis smoothly, and then treat the study and the life positively.

\section{Method}

\section{Participants}

2441 random samples had been taken from vocational college, including 1643 male and 798 female.

\section{Date Collection Method:}

\section{Mental Health Test:}

SCL-90. Revised by Wang Zhengyu. Scoring in 5 points (from 1 to 5) [6]. And UPI(University Personality Inventory). Revised by Fan Fuming.

\section{Implementation:}

2441 questionnaires were issued and valid. The data has been analyzed with SPSS14.0 mathematic statistic software. 


\section{Results}

\section{The Overall the Findings of This Study}

It is the sector, which all the survey factors of SCL-90 reached or exceeded the moderate level (sub-factor $\geq 3$ ), that indicates the apparent division of mental health problems. The result discovered the students' incidence of psychological problems is. In 2441 (measured in the number), there are 329 students with psychological distress, accounted for 13.48\%. Among them, the moderate and severe students were $2.42 \%$, as the Table 1 shows.

Table 1 Statistical table of mental health assessment results (\%)

\begin{tabular}{ccc}
\hline & $\mathrm{N}$ & $\%$ \\
\hline Students with positive symptoms & 329 & 13.48 \\
Students with moderate to severe symptoms & 59 & 2.42 \\
\hline
\end{tabular}

\section{The Comparison of the Characteristics of the Gender and the Mental Health Level}

After multi-factor analysis of variance $n$ the mental health of gender (male and female) $\times$ grade (high-grade low-grade students), it indicated that there is no interaction between two pair factors mentioned above. On the main effect of gender, factors of female students in Depression ( $\mathrm{T}=$ 2.32, $\mathrm{p}<0.05)$, Anxiety $(\mathrm{T}=2.48, \mathrm{p}<0.01)$, Phobia $(\mathrm{T}=5.57, \mathrm{p}<0.001)$ are higher than male students. It appears that female students are prone to occur psychological problems in these three areas (Table 2).

Table 2 The Comparison of gender differences in SCL-90 factors $(\mathrm{x} \pm \mathrm{s})$

\begin{tabular}{ccccccc}
\hline & \multicolumn{2}{l}{ Male } & \multicolumn{2}{l}{ Female } \\
\hline Factors & $\mathrm{N}$ & $\mathrm{X} \pm \mathrm{s}$ & $\mathrm{N}$ & $\mathrm{X} \pm \mathrm{s}$ & $\mathrm{T}$ & $\mathrm{P}$ \\
\hline Somatization & 1643 & $1.16 \pm 0.28$ & 798 & $1.17 \pm 0.30$ & 0.81 & $\mathrm{P}>0.05$ \\
Obsessive & 1643 & $1.55 \pm 0.52$ & 798 & $1.57 \pm 0.53$ & 0.89 & $\mathrm{P}>0.05$ \\
Interpersonal-sensitivity & 1643 & $1.42 \pm 0.47$ & 798 & $1.39 \pm 0.46$ & 1.49 & $\mathrm{P}>0.05$ \\
Depression & 1643 & $1.27 \pm 0.39$ & 798 & $1.31 \pm 0.42$ & 2.32 & $\mathrm{P}<0.05$ \\
Anxiety & 1643 & $1.27 \pm 0.36$ & 798 & $1.31 \pm 0.40$ & 2.48 & $\mathrm{P}<0.01$ \\
Hostile & 1643 & $1.26 \pm 0.40$ & 798 & $1.26 \pm 0.41$ & 0 & $\mathrm{P}>0.05$ \\
Phobia & 1643 & $1.20 \pm 0.35$ & 798 & $1.29 \pm 0.42$ & 5.57 & $\mathrm{P}<0.001$ \\
Paranoid & 1643 & $1.30 \pm 0.39$ & 798 & $1.29 \pm 0.40$ & 0.59 & $\mathrm{P}>0.05$ \\
Psychotic & 1643 & $1.26 \pm 0.36$ & 798 & $1.28 \pm 0.37$ & 1.28 & $\mathrm{P}>0.05$ \\
others & 1643 & $1.28 \pm 0.39$ & 798 & $1.30 \pm 0.39$ & 1.19 & $\mathrm{P}>0.05$ \\
\hline
\end{tabular}

\section{The Comparison of the Most Common Symptoms}

Arrange the total score from high to low, take the five head and then compare their characteristics of the coping styles between the SCL90 and the UPI. The results show that most of the students are overly concerned about appearance and heterosexual intercourse, acute worry and fear of the future, and self-blame or withdraw when facing the stress (Table 3). 
Table 3 The comparison of the coping style between the SCL90 and the UPI (\%)

\begin{tabular}{|c|c|c|c|c|c|c|}
\hline \multirow[b]{2}{*}{ Item } & \multicolumn{3}{|l|}{ SCL90 } & \multicolumn{3}{|l|}{ UPI } \\
\hline & Subject & $\mathrm{N}$ & $\%$ & Subject & $\mathrm{N}$ & $\%$ \\
\hline \multirow{10}{*}{$\begin{array}{l}\text { Copin } \\
\text { g } \\
\text { Styles }\end{array}$} & Worried about sloppine & 148 & & Care about dirty very & 39 & 34.8 \\
\hline & ss or carelessness & 140 & 6.06 & much & 7 & 2 \\
\hline & Trouble remembering $\mathrm{t}$ & & & Don't trust anything & 36 & 32.2 \\
\hline & hings & 144 & 5.90 & $\begin{array}{l}\text { without repeated } \\
\text { confirmation }\end{array}$ & 8 & 8 \\
\hline & Feeling pushed to get & 136 & 5,57 & Having responsibility & 34 & 30.6 \\
\hline & things done & & כ.J/ & too much & 9 & 1 \\
\hline & Feeling shy or uneasy & 131 & 5.37 & Parents' exnect so high & 31 & 27.8 \\
\hline & with the opposite sex & 131 & $3.3 /$ & Parents expect so nign & 7 & 1 \\
\hline & Difficulty making & 121 & 4.96 & Care about other & 30 & 27.1 \\
\hline & decision & 121 & 4.90 & people's sight & 9 & 1 \\
\hline
\end{tabular}

\section{Discussion}

\section{The Mental Health of Students in the Private College}

This analysis of the mental health indicates the students under investigation display the obvious mental health problem in Interpersonal-sensitivity and Obsessive. These result in multiple problems in the human communication. At the same time, the intense study and the bad human communication are related to obsessive behavior. That is why the obsessive also becomes a prominent question.

The research demonstrated that the female student get higher scores than the male obviously in the factors of Depression, Anxiety and Phobia. That tells that the female student have more illness and negative emotion. This is mainly due to the female student entering puberty earlier than the male and they are more sensitive and exquisite so as to experience more mental conflict (such as premenstrual or menstrual tension). The female with the stress susceptible, therefore, should be the focus on dealing with mental stress and promoting their mental health.

\section{The Characteristics of Coping Styles of Students in the Private College}

As the study shows, most of the students are overly concerned about appearance and heterosexual intercourse, acute worry and fear of the future, and self-blame or withdraw when facing the stress. From the view of education, seeking-help and problem-solving are the two better methods for the students, which are willing to change when facing with confusion and deal with the question positively. But their lacking of experience become a shorter board when they making decision. Thus the core task appears to the professional workers, that is how to help the younger students actively to reduce their mental problems effectively as the gender is the significant factor in the psychological consulting or education.

It has not been demonstrated that stress is a concept, which is amenable to measurement. These instruments also rely on an individual's subjective conceptions of their emotions and general physical or mental state. What is less clear is whether problems that are being labeled as stress-related are being caused by stress, or whether stress is simply one of a range of factors encountered while studying at a university. Mental illness is results of fail coping style as an individual under the high stress. Therefore the effective coping style is the key way to prevent an individual from mental illness ${ }^{[3]}$. The students should adjust the coping styles base on their own characteristic. In the case they should master effective ways from multiple means, such as psychological newspaper, to improve the psychological quality and enhance problem-solving skills. Thus the mental illness may be reduced. 


\section{References}

[1]Abouserie, R.. Sources and levels of stress in relation to locus of control and self-esteem in university students. Educational Psychology, (1994), 14(3), 323-330.

[2]Andrews, B., \& Wilding, J. M.. The relation of depression and anxiety to life-stress and achievement in students. British Journal of Psychology, (2004), 95, 509-521.

[3]Huang Xuewei. Research on coping style of college students. Chinese Journal of Behavioral Medical Science, (1999), 8: 273-275

[4]Roberts, R., Golding, J., Towell,T., \& Weinreb, I.. The effects of students' economic circumstances on mental and physical health. The American Journal of College Health, (1999), 6, 23-35.

[5]Schafer, W.. Stress Management for Wellness.(3rd ed.)Fort Worth: Harcourt Brace College Publishers. 1996.

[6]Wang Zhengyu. The Self-Report Symptom Inventory (SCL-90). Shanghai Archives of Psychiatry, (1984),4, 2(2):68-70. 